\title{
Torture and the participation of doctors
}

\author{
Ugur Cilasun Ankara, Turkey
}

It is an established fact that already-existing torture in Turkey, reached its peak of intensity in the immediate aftermath of the 1980 military coup. Despite presentday denials by government authorities, systematic torture is still continuing. Over the past two decades, when democratic processes were interrupted by two military interventions, torture has been applied to all political prisoners, intellectuals, the youth, workers, and ordinary criminals alike. Nothing much has changed.

All those opposed to the mistreatment of prisoners and to torture, should acknowledge the obvious fact that, wherever there is a systematic application of torture, there is involvement on the part of doctors. In other words, if doctors did not participate in, or contribute to, these practices, systematic torture could never be realised. Speaking both universally, and on a national scale, doctor contribution to torture is realised in two main forms:

1. Keeping the prisoner under direct and continuous observation, and, thereby, enabling the torturers to intensify and continue their vile acts;

2. Drawing up false health reports, and, thereby, concealing the signs of torture left on the tortured.

The torturer, on the other hand, resorts to torture, for two specific purposes:

1. To extract information, deemed necessary;

2. To punish the person he visualises as either a national, or personal, enemy.

Under both circumstances, the untimely death of the tortured person both thwarts the original purpose of torture (ie, extraction of information) and, occasionally, creates legal complications for the torturer. For those obvious reasons, it is the desire of every torturer, to extend, as much as possible, the duration of torture, without causing the death of the tortured. Needless to say, the torturer, for this purpose, needs an informed assistant, who can observe the fare of vital functions.

What better specialist than a doctor? In short, the role of doctors, in torture, is that of 'the person who permits torture'.
Viewing this state of affairs from the standpoint of medical ethics, the doctors' second role in torture is just as serious as the first. Since even the most dictatorial governments cannot publicly recognise and legalise torture and, since allegations inevitably crop up, it is in the torturer's vital interest to have falsified medical reports drawn up. The person to falsify medical evidence of torture is, again, the doctor. Doctors contributing to the practice and continuation of torture either draw up their reports without even seeing the tortured, or intentionally omit the signs thereof, which, in turn, provides legal protection for the torturer. Needless to say, after the passing of of certain amount of time, it becomes virtually impossible for the victims of torture, either under arrest, or if custody, to prove that they have been tortured.

Following this overview, I would like to summarise the situation in Turkey.

\section{Working conditions of doctors in Turkey}

The status of doctors in Turkey can be divided into three categories:

1. Those solely in private practice;

2. Those working for the government and continuing their private practice;

3. Those working full-time for the government.

In addition to these three there are also military doctors, to whom I shall refer later.

Since the first category of doctors, ie, those solely in private practice, have no legal responsibility towards, and bonds of material interest with, the government, they are not in any way involved in the practice of torture. No information has reached either the media, or the Turkish Medical Association (TMA), over the past ten years, in connection with an involvement of his sort.

Those involved in the practice of torture are drawn from the remaining two categories, and from among the military doctors. It should be admitted that some doctors may become voluntarily involved in the practice of torture. It is, however, our confirmed belief that such persons constitute a very small minority in the medical community and, that those doctors participating in torture are doing so under threat and/ 
or pressure. Government pressure, on full or part-time employees, emerges in various forms. Doctors who refuse to participate in the act of torture can be accused of not obeying the orders of their immediate superiors and can be either dismissed from government service, or relocated to other posts with highly unfavourable working/living conditions. Material considerations, fear of being removed from family, and the obvious threat of coming under suspicion of 'secretly collaborating with public enemies', etc, exerts such emotional pressure that doctors are forced to participate, directly or indirectly, in the act of torture. As a consequence, the World Medical Association's Tokyo Declaration, to the effect that 'threats of pressure, are not excuses for the mistreatment or torture of human beings', loses its effectiveness when confronted by the facts of everyday life.

The position of military doctors is different. Before 1980 , military doctors received scholarships from the military, but studied medicine in civilian schools. They therefore entered medical practice with a civilian outlook and, furthermore, were obliged to register themselves with the TMA. After legislative changes in the aftermath of the 1980 military coup, a military school of medicine was established for the purpose of training doctors solely for the military. In a ceremony at this military school, the head of the junta, addressing the soldier students, said: 'You are first and foremost soldiers, and only after that, doctors'. This was evidence that military doctors were expected and obliged to give priority to the chain-of-command, above and over the medical code of ethics. Shortly afterwards, medical doctors were forbidden to become registered members of the TMA.

The active and intensive participation of medical doctors in the practice of torture, has received wide publicity in the media. The participants, however, have remained more or less anonymous, due to the severed relations between the civilian and military medical communities.

\section{Difficulties in identifying participants in torture}

As questioning and torture is carried out on blindfolded persons our basic problem is related to the obvious difficulty in identifying those doctors participating in the act of torture. Furthermore, doctor participation in torture is usually called upon when the victim has either lost consciousness, or is in a state of semi-consciousness. The victim, therefore, has almost no chance of seeing or identifying the attending doctor. The victim of torture has a better chance of identifying the doctor who draws up falsified medical reports, but there too, we face difficulties. The victim of torture is taken for medical observation in the company of either a military or a police escort. Needless to say, the presence of these escorts exerts tremendous psychological pressure on both the victim and the doctor. Sensing that the doctor is in a situation more or less similar to his own, the victim does not make too much of an effort to identify the attending doctor. Anyway, in a medical institution with a large number of staff, and in the course of a check-up which lasts a few minutes at the most, it is very difficult to identify one particular person. As a consequence, very few doctors have been publicly named, either in the trials of the victims of torture, or in their registered complaints to the TMA. The same holds true for the actual torturers but to a lesser extent. Since the signed confessions of the prisoners have to be undersigned by the questioners, in order to be accepted as evidence in court, the names of the torturers are more widely known than those of their medical collaborators.

\section{Attitude of the TMA towards doctors participating in torture}

Following the 1980 coup d'état, the activities of the TMA were indefinitely suspended. This suspension continued until the end of 1983 . Immediately prior to the lifting of this suspension however, new legislation was introduced, and serious restrictions were imposed upon the rights, responsibilities, and authority of the TMA. Despite these restrictions, however, the TMA has launched extensive investigations into all claims of doctor-participation in the mistreatment and torture of prisoners. The difficulties in identifying the perpetrators however, have seriously thwarted the administration of medical/professional justice.

The TMA's major contribution to the battle against torture has come in the form of incessant public denouncements of these inhumanities. The TMA has called upon the authorities to put an end to these violations of basic human rights, and has issued calls to the medical community that 'torture and mistreatment of prisoners can never be accepted, even under conditions of acute pressure, and that doctors should outrightly refuse to participate, whatever the consequences'. These efforts, on our part, have contributed to the processes of democratisation in Turkey.

The TMA has established close ties with the Rehabilitation and Research Centre for Torture Victims and has also spared no effort towards the establishment of a treatment centre for the victims of mistreatment and torture. Acting with the Human Rights Association, a joint foundation has been set up. The TMA sees the issue of torture as a vital problem concerning the regime. With the further democratisation of Turkey and the lifting of the socalled 'veils of security' and, henceforth, secrecy, we sincerely believe that torture will eventually come to an end.

Torture, and torturers, exist and flourish only in darkness and secrecy.

Dr Ugur Cilasun, $M D$, is the Executive Director of the Turkish Medical Association, Ankara, Turkey. 